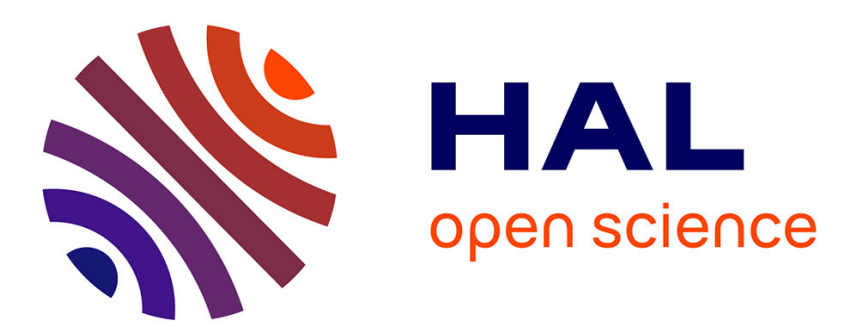

\title{
Inviscid approach for upwind sails aerodynamics. How far can we go?
}

Nicolas Aubin, Benoit Augier, Patrick Bot, Frédéric Hauville, Ronan Floch

\section{To cite this version:}

Nicolas Aubin, Benoit Augier, Patrick Bot, Frédéric Hauville, Ronan Floch. Inviscid approach for upwind sails aerodynamics. How far can we go?. Journal of Wind Engineering and Industrial Aerodynamics, 2016, 155, pp.208-215. 10.1016/j.jweia.2016.06.005 . hal-01591858

\section{HAL Id: hal-01591858 \\ https://hal.science/hal-01591858}

Submitted on 25 Sep 2017

HAL is a multi-disciplinary open access archive for the deposit and dissemination of scientific research documents, whether they are published or not. The documents may come from teaching and research institutions in France or abroad, or from public or private research centers.
L'archive ouverte pluridisciplinaire HAL, est destinée au dépôt et à la diffusion de documents scientifiques de niveau recherche, publiés ou non, émanant des établissements d'enseignement et de recherche français ou étrangers, des laboratoires publics ou privés. 


\title{
Inviscid approach for upwind sails aerodynamics. How far can we go?
}

\author{
N. Aubin ${ }^{\mathrm{a}}$, B. Augier ${ }^{\mathrm{a}, *}$, P. Bot ${ }^{\mathrm{a}}, \mathrm{F}$. Hauville ${ }^{\mathrm{a}}$, R. Floch ${ }^{\mathrm{b}}$ \\ a Institut de Recherche de l'Ecole Navale, IRENav, BCRM de Brest, Ecole navale, CC 600 - Lanveoc, F-29240 BREST Cedex 9, France \\ ${ }^{\mathrm{b}}$ Incidence Sails, 520 rue Alain Colas, 29200 Brest, France
}

Keywords:

Fluid-structure interaction

Numerical simulation

Yacht sails

Full scale measurements

Instrumented boat

Inviscid flow

Aerodynamic forces

Sails flying shape

\begin{abstract}
A B S T R A C T
This work presents a full-scale experimental study of a yacht rig and sails in real upwind sailing conditions and a comparison with Fluid Structure Interaction (FSI) simulations with the ARAVANTI model (Finite Element Method for the structure and Vortex Lattice Method for the fluid). A specific on-board instrumentation system simultaneously measures loads in the rig and sails, sailing data (wind, boat attitude and speed) and the shape of sails in real navigation conditions (flying shape). Flying shape parameters are extracted using the camera-based VSPARS system to characterize the effects of sail trims and to be compared with the results of the simulation. The potential flow solver gives fast and accurate predictions of both the flying shape and the loads in the rig in most conditions. The inviscid approach, commonly used in the early stage of design, must be checked, as in particular cases where the sails are heavily loaded, flow separation is significant and results from a potential flow solver are inaccurate. A new version of the model including the heel angle as an additional degree of freedom in the structural solver enables to detect when the inviscid flow approach overestimates the aerodynamic load. This upgrade improves the utility and reliability of the inviscid flow approach which remains relevant at the early stages of design as it is much more cost-effective than RANS models.
\end{abstract}

\section{Introduction}

The prediction of the aerodynamic performance of yacht sails has improved greatly due to different approaches followed by the research community. Direct measurements based on full-scale experiments in real sailing conditions give data for the design and analysis of the performance. Several previous research programs have developed instrumented yachts to obtain full-scale experimental data via sailing dynamometers like Fujin (Masuyama, 2014), MIT Sailing Dynamometer (Milgram et al., 1993), DYNA (Hochkirch and Brandt, 1999), and LECCO (Fossati et al., 2015a). Other full scale specific instrumented yachts have been developed to measure simultaneously the loads in all the tension points of the rig, the flying shape, the wind data and attitude of the boat (Augier, 2012) or the pressure on sails (Viola and Flay, 2010; Motta et al., 2014). Wind tunnel studies (Flay, 1996a,b; Lasher et al., 2005) have proven to a be a great tool to study the aero-elastic problem of sails in wind. More recently, wind tunnel has been also used to study the Fluid Structure Interaction (FSI) phenomena that occur with sails in dynamic conditions in pitching (Fossati and Muggiasca, 2009) or with a dynamic trimming (Aubin et al., 2016). The recent increase in computation capabilities has allowed the

\footnotetext{
* Corresponding author.

E-mail address: augier.ben@gmail.com (B. Augier).
}

development of accurate CFD tools to model the FSI of sails (Braun and Imas, 2008; Lasher and Sonnenmeir, 2008). However, both results from wind tunnel and particularly CFD need to be validated by full-scale observation. For instance Yoo and Kim (2006) compared CFD results and experimental measurements on yacht sails. IRENav has validated a numerical FSI model with full-scale results achieved on an instrumented J80-class yacht (Augier, 2012; Augier et al., 2012) in both steady and unsteady situations. The model was then used to predict the aerodynamic forces and rig loads of a sailing yacht in dynamic conditions (Augier et al., 2014) and can be used for performance studies. Using an FSI tool can be interesting to predict the effect of trimming the sails and the rig to adapt to the sailing conditions. The FSI tool ARAVANTI (Roux et al., 2008) developed by the K-EPSILON Company and IRENav has already been validated in such situations and has proven to be an accurate prediction tool, even in highly unsteady cases (Augier et al., 2012). The model, based on a potential flow approach is limited to cases where the flow is assumed to be fully attached, i.e. upwind conditions. It is now well known that flow separation may be nonnegligible also in upwind sailing (e.g. Fluck et al., 2010; Fossati and Muggiasca, 2012; Viola et al., 2013). Some studies have already compared the inviscid flow FSI model ARAVANTI to the viscous flow FSI model ARA-ISIS, coupling the same structural code ARA to the RANS solver ISIS-CFD (commercialized as FINETM/Marine), and have highlighted situations where the potential flow approach is 


\begin{tabular}{|llll|}
\hline Nomenclature & $M_{x}$ & heeling moment $(\mathrm{N} \mathrm{m})$ \\
& & $R_{m}$ & righting moment $(\mathrm{N} \mathrm{m})$ \\
$\Delta$ & boat displacement $(\mathrm{kg})$ & ARAVANTI FSI coupling between the structure model ARA and \\
$\phi$ & heel angle $\left({ }^{\circ}\right)$ & the inviscid fluid model AVANTI \\
$F_{X}$ & driving force $(\mathrm{N})$ & FSI & Fluid Structure Interaction \\
$g$ & acceleration of gravity $\left(\mathrm{m} \mathrm{s}^{-2}\right)$ & NMEA & National Marine Electronics Association \\
$G Z$ & hydrostatic righting arm $(\mathrm{m})$ & VSPARS & Visual Sail Position And Rig Shape (Le Pelley and \\
$L$ & moment arm of crew weight $(\mathrm{m})$ & & Modral, 2008) \\
$m$ & crew weight $(\mathrm{kg})$ & & \\
& & \\
\end{tabular}

incorrect (Sacher et al., 2015). However, as viscous flow simulations require a large amount of CPU time (Löhner et al., 2015; Michalski et al., 2015), the potential flow approach is still largely used at early design stages.

The goals of this paper are to measure the effects of sail and rig trims on the sails shape, and to assess the ability of the potential flow FSI tool ARAVANTI to predict aerodynamic loads and sails flying shape. An improved model is also presented, including heel as an additional degree of freedom in the structural model. A simple criterion based on the balance of righting and heeling moments allows the relevance of the potential flow approach to be easily checked. Sections 2 and 3 introduce the experimental and numerical tools used for this study. Section 4 shows the effects of different trims (sheeting car position) on the sails shape. In Section 5, experimental results are compared to FSI simulations for two different cases of backstay tension: one where the simulation is correct and one where the inviscid flow assumption is violated. The latter case is better analyzed in Section 6 thanks to the upgraded model. A few concluding remarks are made in the last section.

\section{Measurements}

\subsection{System apparatus}

Full-scale measurements are performed on a J80-class yacht, an $8 \mathrm{~m}$ one-design cruiser-racer boat. A specific instrumentation described in Augier et al. (2012) is used to measure the loads in 16 points of the rig, the yacht motion and attitudes, the sails flying shape and navigation parameters. Mainsail and jib luffs are hanked on, foots and leeches are loose. The instrumented boat is presented in Fig. 1. In the present setup, the on-board acquisition system is divided into two parts: one is in charge of recording all the navigation and load data (rig loads, wind information, boat speed and attitude, etc.) and the other one is in charge of the flying shape acquisition (based on deck-mounted GoPro cameras filming stripes taped on the sails). A triggered laser pulse is used to synchronize the video with the recorded data. Motions and attitudes are recorded using an SBG Systems@motion sensor. Wind data are recorded using a 3D ultrasonic anemometer and Nke@ wind vane and cup anemometer placed at the top of the mast. Loads are measured with specific instrumented shackles and turnbuckles fitted with strain gauges that replace the classical fittings. The precision error on the loads is less than $2 \%$ over a $10000 \mathrm{~N}$ range for the rig and $5000 \mathrm{~N}$ for the sails' lines. The upwind experiments presented herein were carried out in the bay of Brest in June 2014 with a North Westerly wind of $12.5 \mathrm{kn}$ in average and calm water.

\subsection{Data post-processing}

Special care was taken in data post-processing to cope with the high number and heterogeneity of the recorded data. Navigation

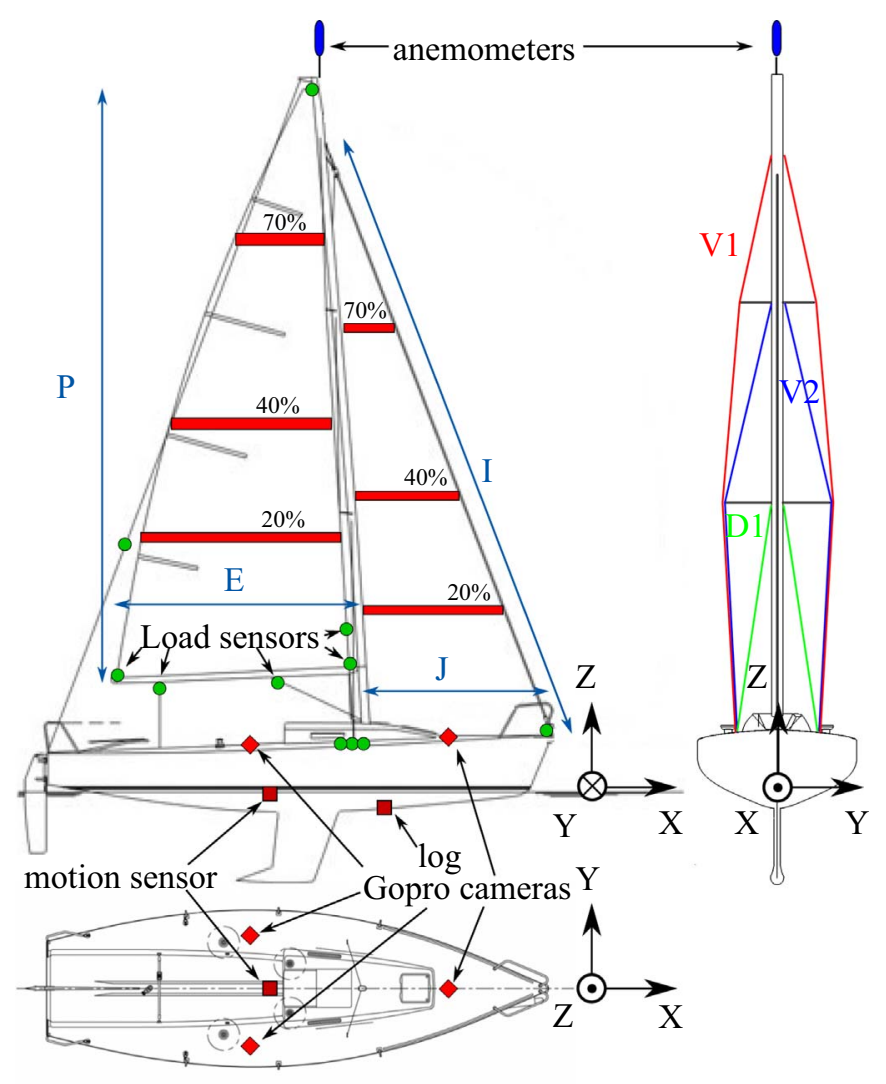

Fig. 1. Yacht system apparatus.

data such as boat speed from the loch, GPS data, Nke company@wind sensors and motion sensor are gathered and recorded by the Nke company@system using the NMEA protocol. That information is sent and time-stamped at reception by a Compact Rio acquisition unit, which also directly receives the analog signals from the load sensors $(25 \mathrm{~Hz})$, the 3D anemometer $(10 \mathrm{~Hz})$ and another motion sensor (free IMU). Each sensor records the corresponding signal with its own sampling frequency, therefore resampling is applied to obtain synchronous data.

\subsection{Flying shape analysis}

Several techniques can be used to measure the 3D flying shape of sails such as laser scanning (Fossati et al., 2015b) or photogrammetry (Mausolf et al., 2011). In this study, sails fitted with taped stripes are visualized by 3 deck-mounted Gopro cameras and the VSPARS system is used to provide the 3D stripe coordinates in the boat frame (Le Pelley and Modral, 2008). Three stripes per sail were used: stripe 1 at 20\% (lower stripe), stripe 2 at $40 \%$ (middle stripe) and stripe 3 at 70\% (upper stripe) of the luff length (Fig. 1). After synchronizing the video with the other recordings using the 


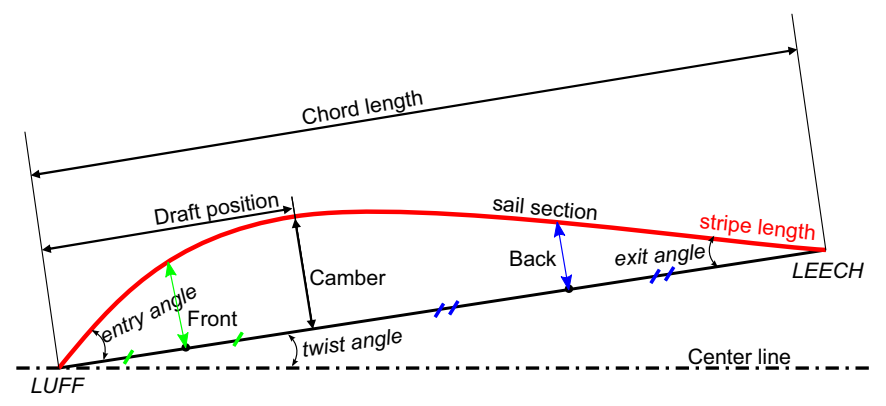

Fig. 2. Stripe parameters of the sail.

laser pulses, each video frame is extracted as an image and timestamped. A calibration is applied to correct the so-called 'fish-eye' lens distortion. Flying shape of the sails is characterized with stripe parameters (defined in Fig. 2) commonly used to define sails aerodynamic sections. This allows quantitatively analyzing the sails shape and the effects of trimming.

\section{Numerical simulation}

\subsection{Numerical model}

Inviscid models have been used for a long time in sail aerodynamics (e.g. Fiddes and Gaydon, 1996; Gerhardt et al., 2011). Despite the development of more advanced models, the inviscid approach is still commonly used in the early design stage because it is very fast. The FSI model ARAVANTI from K-EPSILON Company is used for the numerical simulations in upwind situations presented here. The structural solver ARA is a Finite Element Method model. Sails are described with constant strain triangle membrane elements, the mast, boom, spreaders and battens use beam elements, while shrouds and running rigging use wire elements. The rig's structural properties have been measured (Augier et al., 2012) and the sails' materials and structural properties were provided by Incidences Sailmaker. The AVANTI flow solver is a Vortex Lattice Method modelling an inviscid flow. The sails' surface is described using rectangular panels and the wake is modelled with particles. More details about the coupling scheme can be found in Roux et al. (2008). The ability of ARAVANTI to accurately predict aerodynamic loads and the flying shape of the sails in both steady and unsteady situations has been shown in Augier et al. (2012).

\subsection{Simulation and experimental comparison process}

The method for numerical simulation based on experimentally recorded inputs is illustrated in Fig. 3. As this work deals with steady-state simulations, only experimental runs with near-steady situations are considered and data are time-averaged over a $10 \mathrm{~s}$ run. The following parameters are determined from the selected experimental run and given as inputs to the numerical simulation:

- true wind: determined from the measured Apparent Wind Speed (AWS), Apparent Wind Angle (AWA) and boat speed, assuming a logarithmic profile over the sea surface, with a roughness length $z_{0}=0.2 \mathrm{~mm}$ (Flay, 1996a);

- length of shrouds, and trimming lines from the running rigging manually measured for each run; concerning the backstay, the measured tension is used as input;

- structural mechanical properties either given by the sail maker or measured for each rig item (Augier et al., 2012);

- boat attitudes and speed: in the first approach, trim, heading and heel angles are set to the measured values and fixed in the

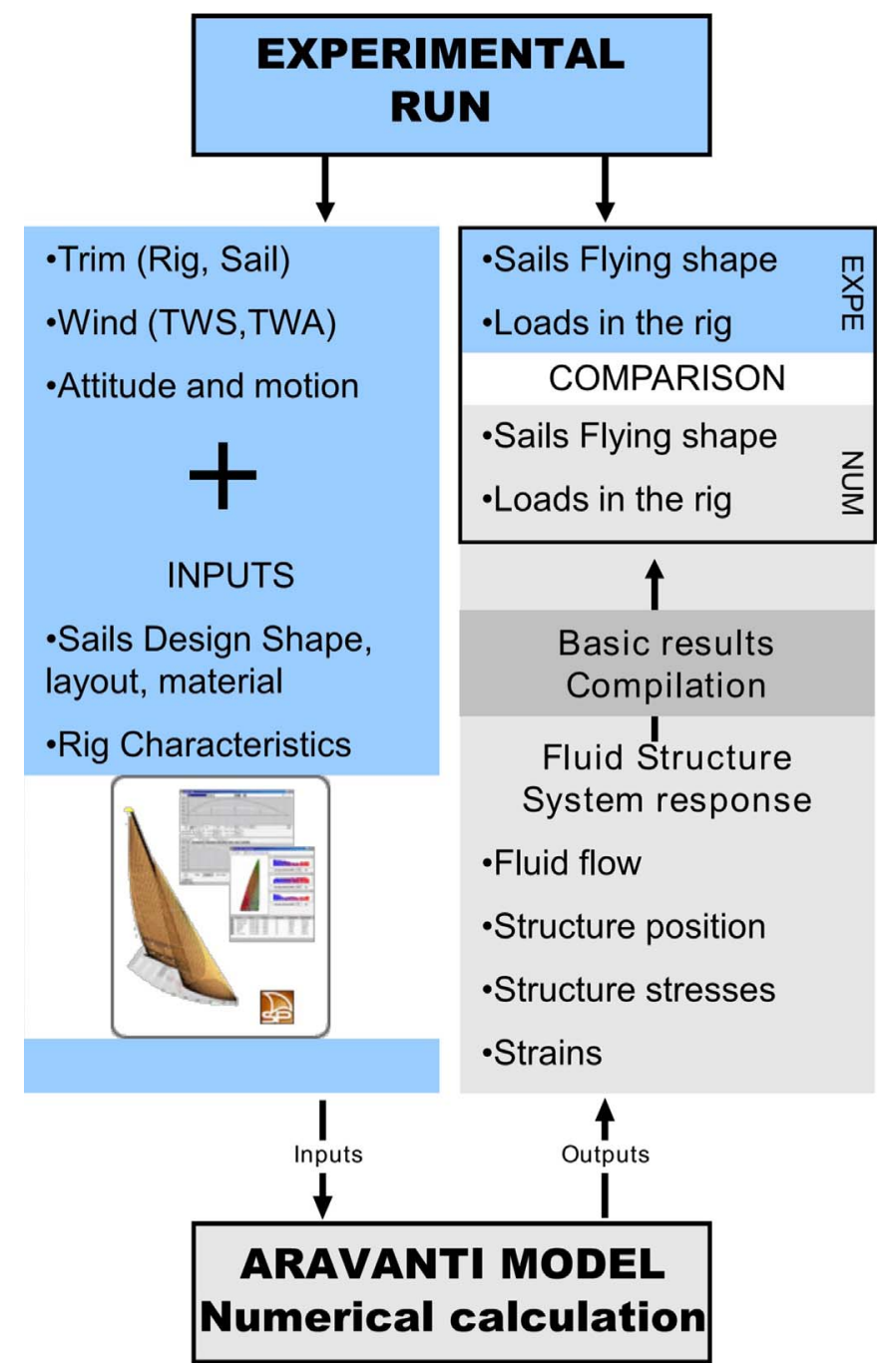

Fig. 3. Method for numerical calculation representing an experimental situation and experimental validation.

simulation; in the second approach described in Section 6, the heel angle is not fixed but is an additional degree of freedom in the structural solver, and the FSI iteration loop converges to balance heeling and righting moments.

The comparison of experimental and simulation results is made on the flying shape of the sails and the loads in the rig (and the heel angle in the second approach).

\section{Effects of trimming on flying shape of the sail}

The flying shapes of the sails are recorded for different cases of trim consisting in changing the jib and mainsail sheeting car position on the travellers, in constant sailing conditions.

\subsection{Jib car position}

Three different jib car positions on the longitudinal traveller were tested (illustrated in Fig. 4): the position $\# 9,5 \mathrm{~cm}$ aft from the reference position \#10, positions \#11 and \#12, respectively $5 \mathrm{~cm}$ and $10 \mathrm{~cm}$ in front of the reference position \#10. Position \#9 is used to flatten the jib in case of stronger breeze. Positions \#11 and \#12 are used to increase the camber in order to get more power in the jib in case of light winds or waves. When the car 


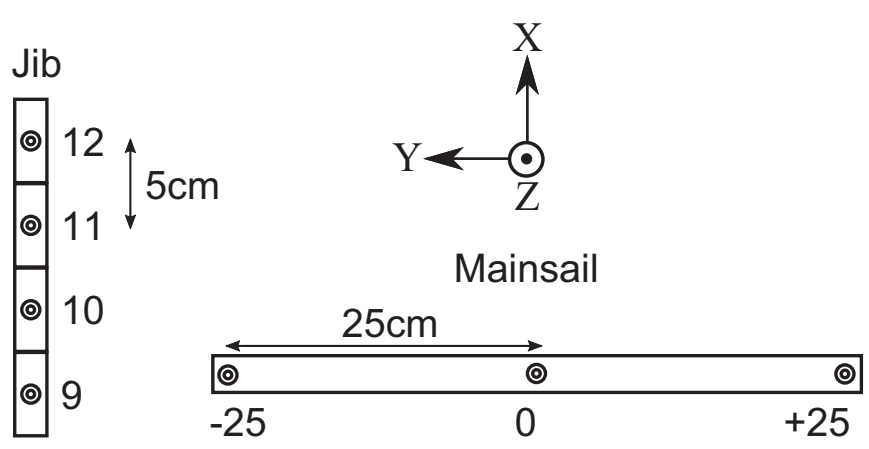

Fig. 4. Positions of the jib and mainsail traveller.

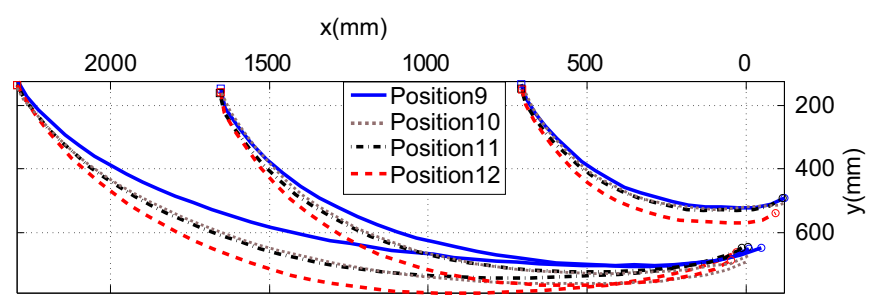

Fig. 5. Jib stripes for different jib car positions, from \#9 (aft) to \#12 (forward).

position was changed, the jib sheet was adjusted for the best trim.

Fig. 5 shows the jib shape for each case. When the car is moved forward, the camber is higher especially for the lower part of the sail where the camber increases from $11 \%$ at position $\# 9$ to $17 \%$ at position \#12. The measured effects on the volume of the sail correspond to the evolution desired by sailors described previously. Note that the twist is not much affected, but this is because the main reference used by the trimmer during these runs is to align the jib leech with the same mark on the first spreader, resulting in a constant twist between stripes 2 and 3 . The higher sail camber is related to the observed increase in heel (from $22^{\circ}$ to $25^{\circ}$ ) and in forestay load (by $300 \mathrm{~N}$ ).

\subsection{Mainsail car position}

The mainsail flying shape is presented for three positions of the main car on the transverse traveler: position 0 on the yacht centerline, position +0.25 at $0.25 \mathrm{~m}$ to leeward, position -0.25 at $0.25 \mathrm{~m}$ to windward (Fig. 6). Contrarily to what was done during the jib car tests presented in the previous subsection, the main sheet was not changed during these 3 cases. The position of the main car is used to alter the sheeting angle, in order to point to an angle closer to the wind when the car is moved to windward, or to increase boat speed when the car is moved to leeward. As can be seen on the measured mainsail shapes, the camber and draft are not affected by adjusting the car's position, but only the sheeting angle and twist vary. Hence, trimming the main car results in rotating aerodynamic sections around the mast. However, when the car is moved $0.5 \mathrm{~m}$ to windward (from position +0.25 to position -0.25 ), the sail's trailing edge is moved to windward by only $0.19 \mathrm{~m}$ on stripe 1 , by $0.05 \mathrm{~m}$ on stripe 2 , and to leeward by $0.05 \mathrm{~m}$ on stripe 3 . This reveals that the sail is more twisted even if the sheet length remains the same, due to higher aerodynamic loading stretching the leech. As the main car is moved to windward (from position -0.25 up to +0.25 ), the measured boat speed decreases from $6.1 \mathrm{kn}$ down to $5.9 \mathrm{kn}$, the AWA decreases from $26^{\circ}$ to $23^{\circ}$ and heel angle increases from $18^{\circ}$ to $21^{\circ}$. The recorded sailing data confirms the expected trends desired by sailors.

The information on the flying shape of the sails measured as a function of trim not only corresponds to the common observations done by sailors when trimming but also enables a real quantitative analysis of the evolution of the aerodynamic profiles resulting from these adjustments and the FSI behavior. Sail makers and trimmers could use the measured values in their optimization process.

\section{Backstay trimming - experimental numerical comparison}

The effect on sails shape of the backstay tension is now studied and a numerical-experimental comparative analysis is performed. The cases presented here correspond to two upwind port side tack runs of $7 \mathrm{~s}$ duration. During the first run, the backstay is trimmed for sailing upwind in the prevailing wind according to an experienced sailor (backstay ON). For the second run, the backstay is released (backstay OFF) when other parameters are fixed, thus the main sheet length remains the same. Table 1 gives the averaged measured parameters used as inputs to the simulation for each case.

\subsection{Flying shape}

Fig. 7 shows the superposition of photographs from the experimental test with the computed sails shape after convergence of the FSI simulation. The rig and flying shape of the sails from experiments and simulation are in very good agreement. The numerical stripes are defined as cross sections of the predicted sails shape with planes at constant heights in the boat frame (heeled plane). These numerical stripes do not exactly match the physical experimental stripes taped on the sails as the latter are not exactly at constant height in the boat frame. Hence, numerical and experimental stripes are not exactly superimposed in Fig. 7 even if the 3D sails' shapes are the same. More quantitative assessment can be made thanks to the stripe parameters.

Figs. 8 and 9 give the evolution of geometrical parameters of the stripes for the jib and the mainsail with the backstay tension ON. Concerning the jib, tightening the backstay increases the draft for an almost constant camber, increases the twist and decreases the entry angle. Effects on the mainsail are to decrease camber and increase the twist, particularly in the higher sections. These observations are consistent with the common knowledge of sailors

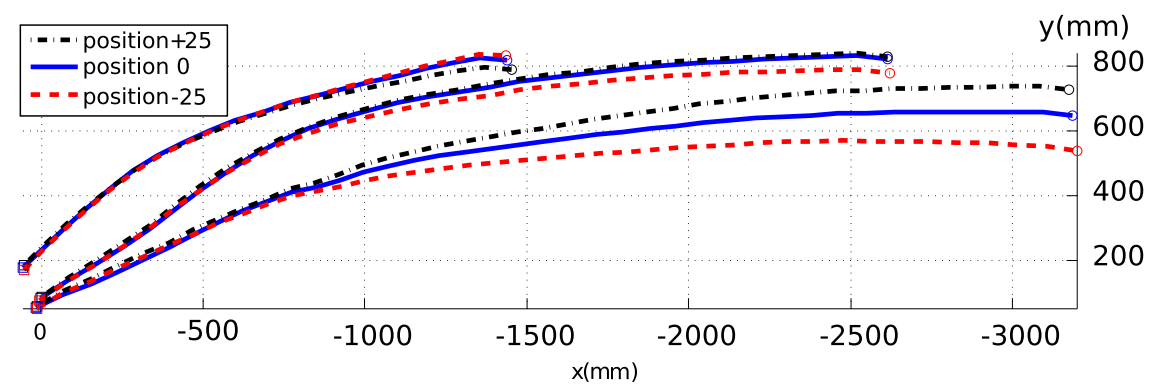

Fig. 6. Mainsail stripes for different mainsail car positions $(-0.25 \mathrm{~cm}$ is for the leeward position and $+0.25 \mathrm{~cm}$ for the windward position). 
Table 1

Numerical input parameters for backstay cases, corresponding to experimental conditions.

\begin{tabular}{lll}
\hline Backstay case & ON & OFF \\
\hline Heel angle $\phi\left(^{\circ}\right)$ & 20.7 & 25.3 \\
Boat speed $(\mathrm{kn})$ & 6.02 & 5.85 \\
AWS $(\mathrm{kn})$ & 17 & 17.5 \\
AWA $\left(^{\circ}\right)$ & 27 & 30 \\
Backstay load $(\mathrm{N})$ & 1957 & 770 \\
\hline
\end{tabular}

and related to increasing the mast bend and decreasing the forestay sag, resulting in flattening the sails and twisting them more to allow pointing to a higher wind angle and reducing heel. These trends are well resolved by the FSI simulations. The experimental setup used in this work allows the effects of backstay tension to be quantitatively measured, and the simulation tool enables one to predict them along with the associated flying shape of the sails. Furthermore, the superposition of simulation results on recorded pictures shown in Fig. 7 allows a display in augmented reality, as in this example showing the strains in the sails, a very useful piece of information for sail designers.

\subsection{Load comparison}

The loads in the rig are shown in Fig. 10 from the experimental tests and the simulation, in both cases with backstay ON and OFF. Good overall agreement is found between the measured and predicted loads, and their variation with the backstay tension is well resolved. In general, loads are increased when the backstay is released - except for the case of the forestay - showing higher aerodynamic loads due to fuller sails.

When the backstay is eased, the loads in the rig, and particularly in the V1 shroud, are overestimated in the simulation (Fig. 10). This indicates that aerodynamic forces are overestimated by the model - excess of $800 \mathrm{~N}$ on all measured loads for backstay OFF, default of only $7 \mathrm{~N}$ for backstay $\mathrm{ON}$ - and particularly on the upper part of the sail. Indeed, due to lack of twist, the upper part of the sail has a greater angle of attack and may be subjected to a separated flow. This flow separation is not modelled by the inviscid flow solver and induces an overestimation of the load transferred to the shrouds.

\subsection{Limit of the inviscid approach}

The inviscid fluid approach used in this study gives accurate

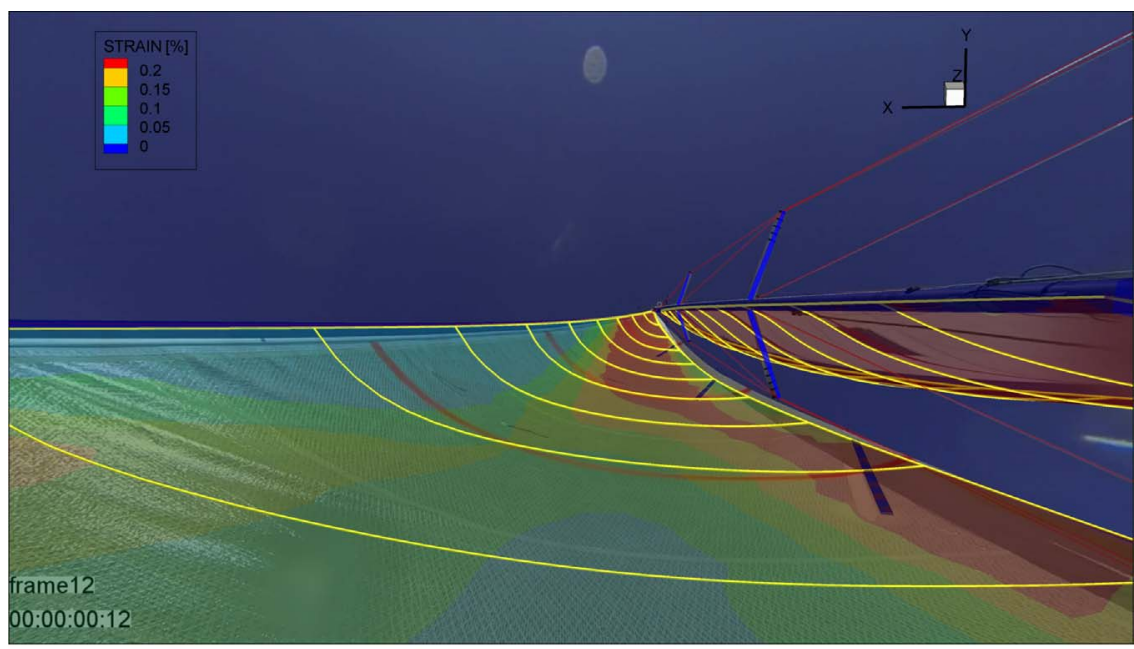

(a) Jib

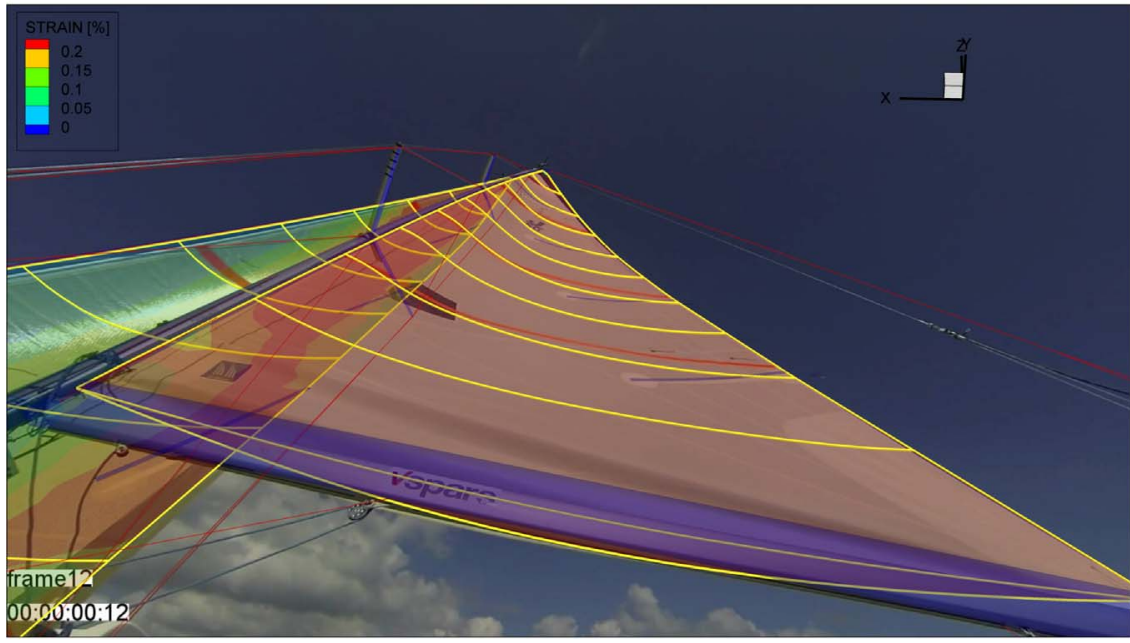

(b) Mainsail

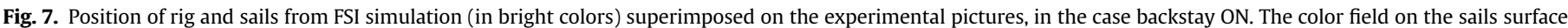
represents the strain in the fabric. (For interpretation of the references to color in this figure caption, the reader is referred to the web version of this paper.) 

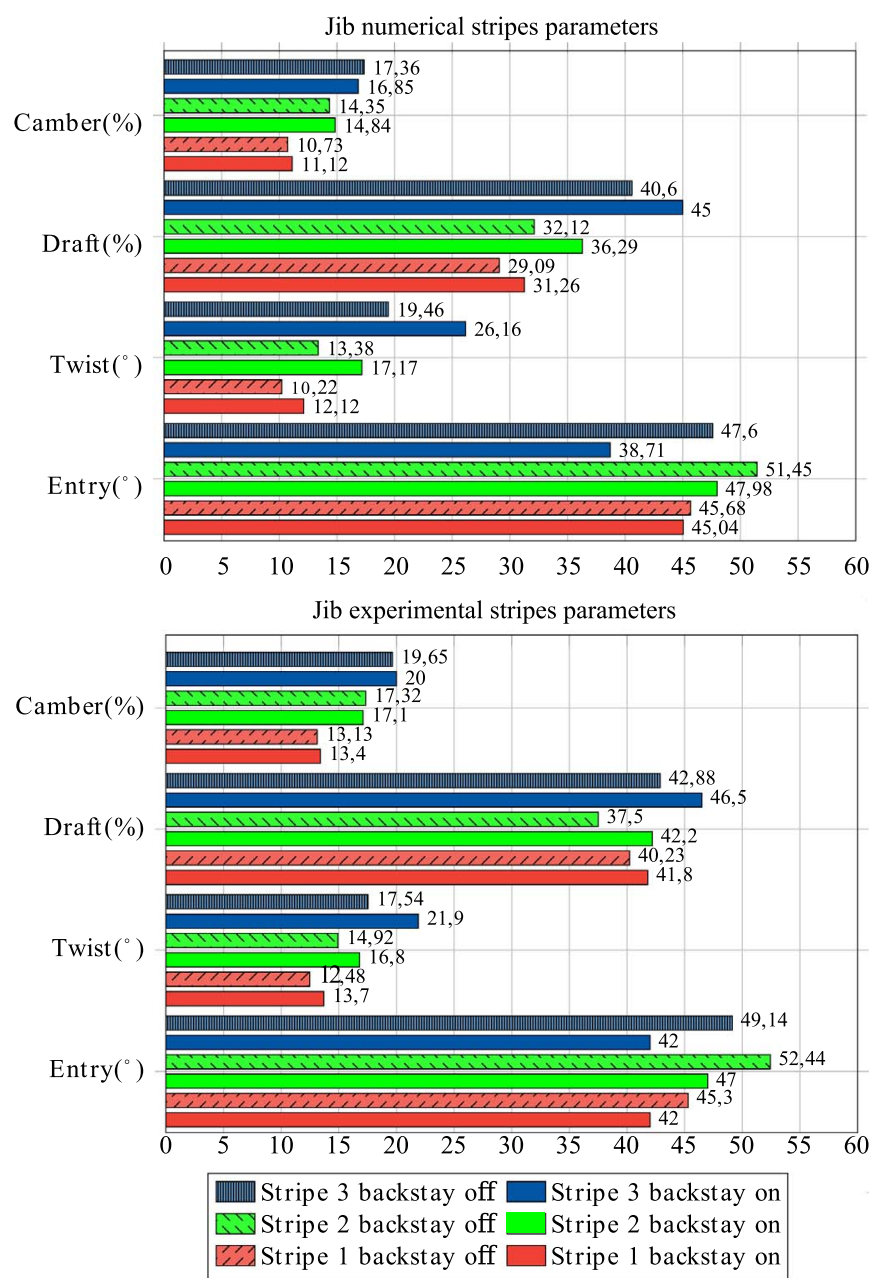

Fig. 8. Jib experimental and numerical stripe parameters.

numerical results with a considerably shorter simulation time compared to RANS models. This potential flow approach is proven here to be very useful and adapted to the described condition backstay ON. Nevertheless, the inviscid approach is limited to cases where the flow can be considered fully attached, a consequential hypothesis that needs to be checked. In upwind sailing with flat and twisted sails such as the presented backstay ON case, this is mostly the case, but it is known that there are situations where flow separation is significant even in upwind sailing, particularly in light wind conditions when the sails are fuller and not twisted much (Sacher et al., 2015; Viola et al., 2013). The sails top sections are particularly prone to flow separation. In the second case backstay OFF, sails are fuller and much less twisted. One may wonder whether the flow remains attached to the suction side of the sails, particularly on the highest sections, and consequently whether the potential flow approach is still valid. If the real flow is significantly detached, a potential flow simulation would overestimate the aerodynamic lift by considering a fully attached flow. The next section presents a simple testing process to assess whether the potential flow aerodynamic forces are realistic by checking the heeling balance.

\section{Free heel simulation}

While previously presented simulation results were obtained with a fixed heel angle (measured in the experiments), an
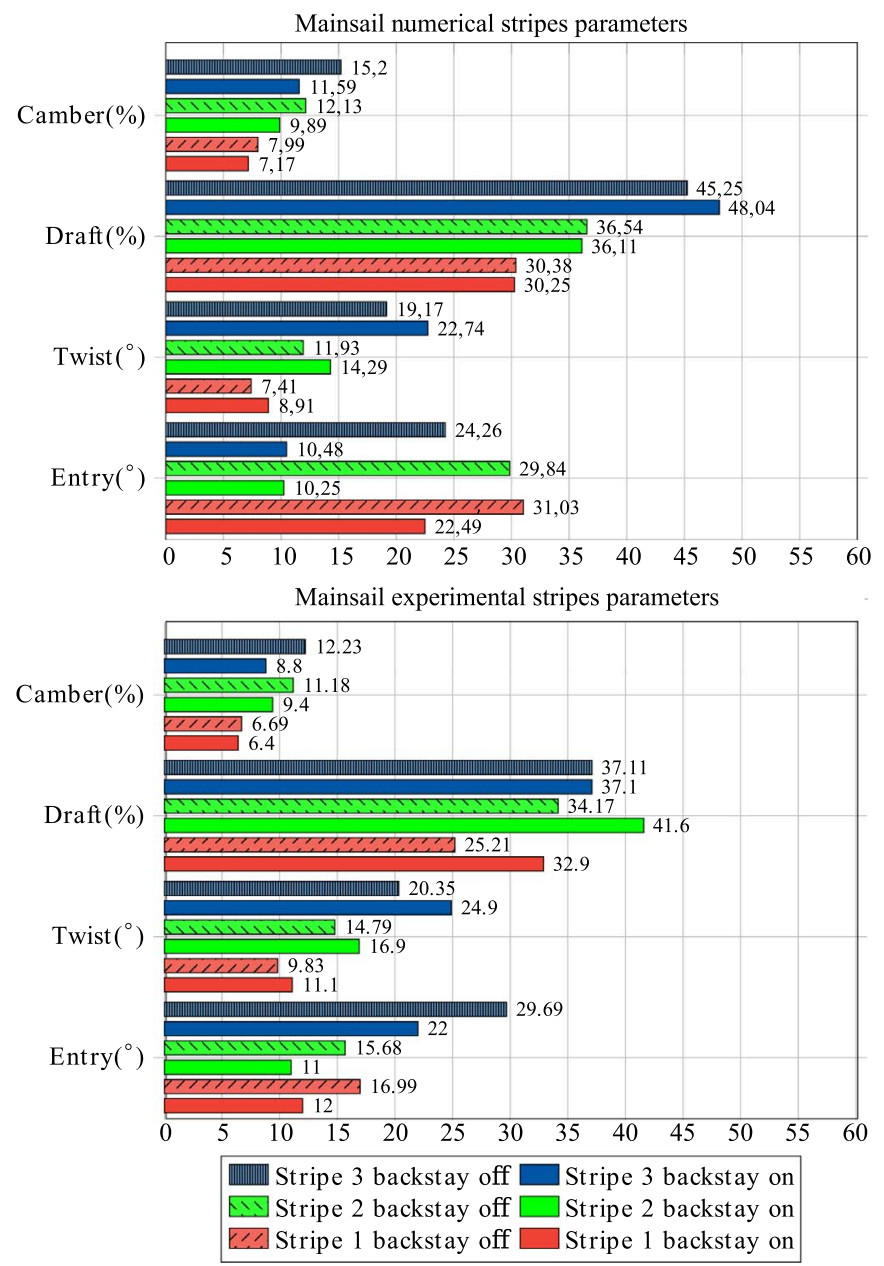

Fig. 9. Mainsail experimental and numerical stripe parameters.

upgraded version of the model is now applied with the heel angle as an extra degree of freedom in the structural solver. Indeed, the whole deformable structure resolved in the FSI loop is now free to rotate around a given axis defined by the yacht's center of gravity and its centerline. The righting moment as a function of the heel angle is an input to the FSI model, given by a hydrostatic analysis of the hull, and the FSI loop converges to the heeling balance between heeling $\left(M_{x}\right)$ and righting $\left(R_{m}\right)$ moments. The static righting moment table is computed with the in-house hydrostatic solver Grinnaert (2010), based on the geometry of the J80 yacht hull, previously measured by photogrammetry. The hydrostatic model gives the righting arm $G Z$ as a function of the heel angle, and the righting moment $R_{m}$ of the yacht including the crew's weight $m=300 \mathrm{~kg}$ can be calculated as:

$R_{m}=(G Z(\phi) \times \Delta+L \times m \times \cos \phi) g$

with $L=1.2 \mathrm{~m}$ for the moment arm of the crew's weight and $\Delta=1400 \mathrm{~kg}$ for the boat's displacement. Fig. 11 shows the computed heeling moment compared to the balance curve $R_{m}=M_{x}$. While the fixed-heel simulation result is very close to the balance curve in the backstay ON case, the backstay OFF case is relatively far from the heel balance. When the simulation is run with free heel, balance is reached at an angle $\phi=31.8^{\circ}$, which is much higher than the experimental one $\left(\phi=25.3^{\circ}\right.$, see Table 1$)$. It is clear from this result that the heeling moment, and thus the whole aerodynamic force are overestimated by the potential flow solver, and one can infer that the inviscid assumption is not verified in the backstay OFF case. Moments and angles for the free heel 


\section{backstay ON Expe 首 backstay ON Num - backstay OFF Expe 䀚backstay OFF Num}
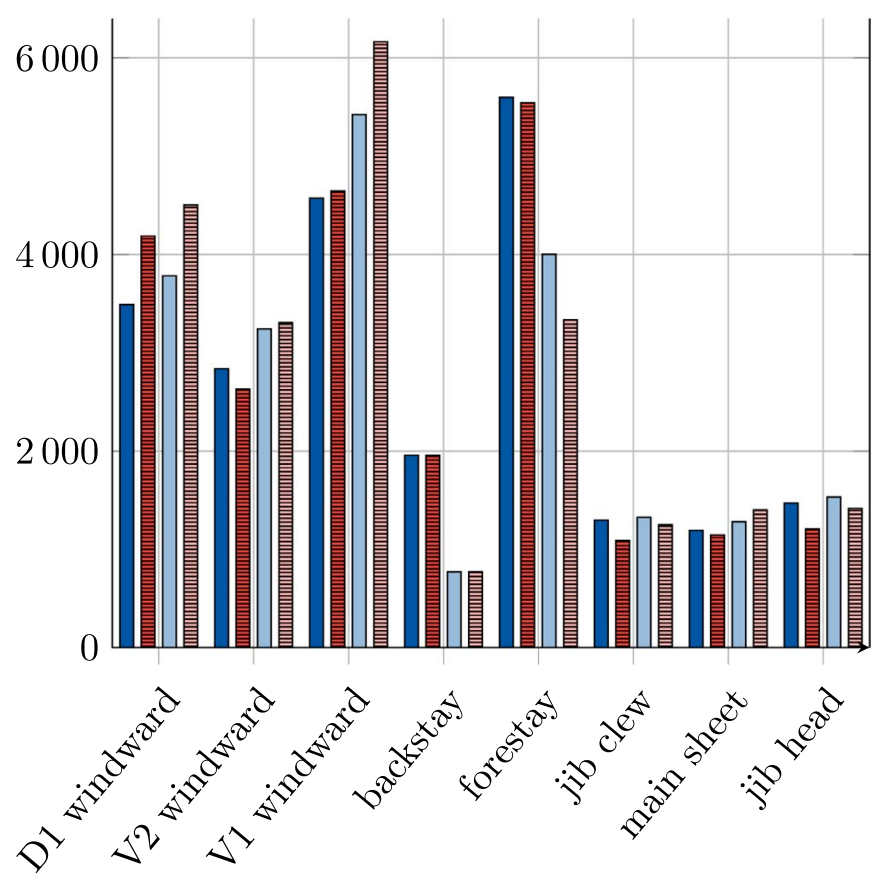

Fig. 10. Numerical and experimental comparison of the loads in the rig for backstay ON and OFF.

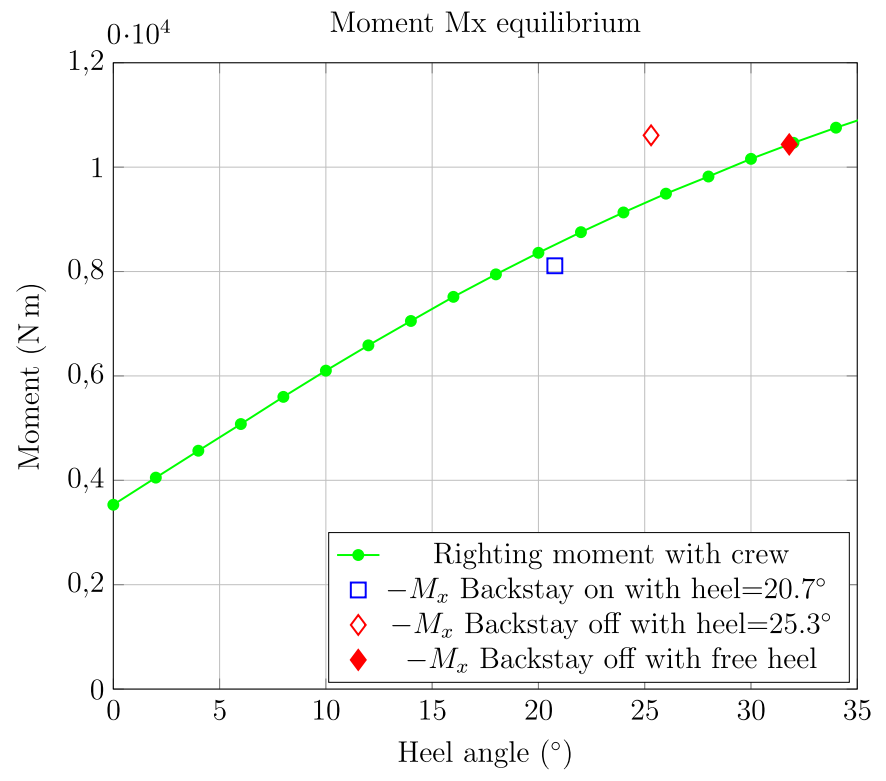

Fig. 11. Heeling moment and balance with righting moment.

Table 2

Output parameters for free heel calculation.

\begin{tabular}{lll}
\hline Backstay case, free heel & ON & OFF \\
\hline$F_{X}$ driving force $(\mathrm{N})$ & 529 & 632 \\
$M_{x}$ heeling moment $(\mathrm{N} \mathrm{m})$ & 8512 & 10436 \\
Heel angle at equilibrium $\left(^{\circ}\right)$ & 20.8 & 31.8 \\
Heel difference with the imposed heel model (\%) & 0.6 & 25.7 \\
\hline
\end{tabular}

simulations are summarized in Table 2.

Considering the balance of the boat in heel is a significant improvement in the simulations to spot cases where the inviscid approach is invalid. Indeed, the user must check the values of righting and heeling moments as they will underline if the computed aerodynamic force is realistic or not. In this particular case backstay OFF, the fact that $R_{m} \neq M_{x}$ would warn the user that the simulations are not realistic and that the results from the potential flow solver are inaccurate. In addition, from a trimming optimization point of view, the simulation result shows that the yacht is overpowered and that sails should be flattened and further twisted. More generally, the free heel simulation is a very useful option which allows the user to input the yacht's heel into a Velocity Prediction Program (VPP), which fits closer to the classical design process.

\section{Conclusions}

This study presents full-scale tests of a yacht sailing upwind with investigation of the flying shape of the sails resulting from different trims. Effects of different trims are quantitatively characterized using the on-board instrumentation system and VSPARS for measuring the flying shape for different trims of the jib and main sheet (adjusting the car position on travelers) and for different values of the backstay tension. The aeroelastic deformation of the sail, i.e. the resulting flying shape of the sails, is accurately predicted in the simulations with the FSI model ARAVANTI - Finite Element structural solver coupled to a potential flow solver. The flying shape of the sails and aerodynamic loads measured at fullscale in real sailing conditions and their prediction with fast FSI simulations are interesting inputs for sail or rig designers, naval architects and sailors (e.g. Shankaram et al., 2002). Inviscid fluid solvers are convenient and commonly used for upwind sailing in the early design stages because they allow a very fast investigation compared to viscous models. However, even in upwind situations, flow separation on the sails may be non-negligible and the challenge for the designer is to determine when the results from potential flow models are no longer reliable. Running a RANS model to check this is very time consuming (Graf et al., 2014). A new feature in the ARAVANTI model with the heel angle as an extra degree of freedom enables the reliability of the potential flow assumption to be rapidly assessed by checking the balance of heeling and righting moments. Indeed, for a separated flow, a potential flow solver would overestimate the aerodynamic forces. It would in particular predict an excessive heeling moment. This simple criterion allows us to detect when significant flow separation occurs without running a full RANS calculation. Moreover, when the fully attached flow assumption is valid, accurately predicting the heel angle is very useful for performance prediction. Future work will be devoted to developing models to account for flow separation as a correction to the inviscid fluid model, based on investigations with RANS CFD.

\section{Acknowledgments}

The authors are grateful to Nke, VSPARS and K-EPSILON Company for continuous collaboration. The authors would like to warmly thank Alcino Ferreira for his review and remarks. This work was supported by Brest Métropole Océane, Région Bretagne (SAD-V1-2014) and the European Union's Seventh Framework Programme (FP7/2007-2013) under REA grant agreement no. PCOFUND-GA-2013-609102 (PRESTIGE-Campus France). 


\section{References}

Aubin, N., Augier, B., Bot, P., Hauville, F., Sacher, M., 2016. Wind tunnel investigation of dynamic trimming on upwind sail aerodynamics. In: Proceedings of the 22th Chesapeake Sailing Yacht Symposium. Annapolis, USA.

Augier, B., 2012. Experimental Studies of FSI on Soft Membrane. Application to Yacht Sails (Ph.D. thesis). Université de Bretagne Occidentale.

Augier, B., Bot, P., Hauville, F., Durand, M., 2012. Experimental validation of unsteady models for fluid structure interaction: application to yacht sails and rigs. J. Wind Eng. Ind. Aerodyn. 101, 53-66.

Augier, B., Hauville, F., Bot, P., Aubin, N., Durand, M., 2014. Numerical study of a flexible sail plan submitted to pitching: hysteresis phenomenon and effect of rig adjustments. Ocean Eng. 90, 119-128.

Braun, J.B., Imas, L., 2008. High fidelity CFD simulations in racing yacht aerodynamic analysis. In: Proceedings of the 3rd High Performance Yacht Design Conference. Auckland, New-Zealand.

Fiddes, S.P., Gaydon, J.H., 1996. A new vortex lattice method for calculating the flow past yacht sails. J. Wind Eng. Ind. Aerodyn. 63, 35-59.

Flay, R.G.J., 1996a. A twisted flow wind tunnel for testing yacht sails. J. Wind Eng. Ind. Aerodyn. 63, 171-182.

Flay, R.G.J., 1996b. J. Wind Eng. Ind. Aerodyn. (Special issue on sail 63(1), vii-ix.

Fluck, M., Gerhardt, F.C., Pilate, J., Flay, R.G.J., 2010. Comparison of potential flowbased and measured pressure distributions over upwind sails. J. Aircr. 47 (6), 2174-2177.

Fossati, F., Bayati, I., Orlandini, F., Muggiasca, S., Vandone, A., Mainetti, G., Sala, R. Bertorello, C., Begovic, E., 2015a. A novel full scale laboratory for yacht engineering research. Ocean Eng. 104, 219-237.

Fossati, F., Mainetti, G., Malandra, M., Sala, R., Schito, P., Vandone, A., 2015b. Offwind sail flying shapes detection. In: Proceedings of 5th High Performance Yacht Design Conference. Auckland, New-Zealand.

Fossati, F., Muggiasca, S., 2009. Sails aerodynamic behavior in dynamic condition. In: Proceedings of the 19th Chesapeake Sailing Yacht Symposium. Annapolis, USA.

Fossati, F., Muggiasca, S., 2012. An experimental investigation of unsteady sail aerodynamics including sail flexibility. In: Proceedings of 4th High Performance Yacht Design Conference. Auckland, New-Zealand.

Gerhardt, F.C., Flay, R.G.J., Richards, P., 2011. Unsteady aerodynamics of two interacting yacht sails in two dimensional potential flow. J. Fluid Mech. 668, $551-581$.

Graf, K., Hoeve, A.v., Watin, S., 2014. Comparison of full 3D-RANS simulations with 2D-RANS/lifting line method calculations for the flow analysis of rigid wings for high performance multihulls. Ocean Eng. 90, 49-61.

Grinnaert, F., 2010. Calcoque: Hydrostatic Calculation Software. URL 〈http://www. calcoque.fr/>.

Hochkirch, K., Brandt, H., 1999. Fullscale hydrodynamic force measurement on the Berlin sailing dynamometer. In: 14th Chesapeake Sailing Yacht Symposium. Annapolis, pp. 33-44.

Lasher, William C., Sonnenmeir, James R., 2008. An analysis of practical RANS simulations for spinnaker aerodynamics. J. Wind Eng. Ind. Aerodyn. 96 143-165. http://dx.doi.org/10.1016/j.jweia.2007.04.001.

Lasher, William C., Sonnenmeir, James R., Forsman, David R., Tomcho, Jason, 2005. The aerodynamics of symmetric spinnakers. J. Wind Eng. Ind. Aerodyn. 93, 311-337. http://dx.doi.org/10.1016/j.jweia.2005.02.001.

Le Pelley, D.J., Modral, O., 2008. V-SPARS: a combined sail and rig shape recognition system using imaging techniques. In: 3rd High Performance Yacht Design Conference. Auckland, New-Zealand, pp. 57-66.

Löhner, R., Haug, E., Michalski, A., Muhammad, B., Drego, A., Nanjundaiah, R., Zarfam, R., 2015. Recent advances in computational wind engineering and fluid structure interaction. J. Wind Eng. Ind. Aerodyn. 144, 14-23. http://dx.doi.org/ 10.1016/j.jweia.2007.04.001.

Masuyama, Y., 2014. The work achieved with the sail dynamometer boat "Fujin", and the role of full scale tests as the bridge between model tests and CFD. Ocean Eng. 90, 72-83.

Mausolf, J., Deparday, J., Graf, K., Renzsh, H., Böhm, C., 2011. Photogrammetry based flying shape investigation of downwind sails in the wind tunnel and at full scale on a sailing yacht. In: 20th Chesapeake Sailing Yacht Symposium. Annapolis, USA.

Michalski, A., Gawenat, B., Gelenne, P., Haug, E., 2015. Computational wind engineering of large umbrella structures. J. Wind Eng. Ind. Aerodyn. 144, 96-107.

Milgram, J.H., Peters, D.B., Eckhouse, N., 1993. Modelling IACC sail forces by combining measurements with CFD. In: Proceedings of the 11th Chesapeake Sailing Yacht Symposium. Annapolis, USA

Motta, D., Flay, R.G.J., Richards, P.J., Le Pelley, D.J., Deparday, J., Bot, P., 2014. Experimental investigation of asymmetric spinnaker aerodynamics using pressure and sail shape measurements, Ocean Eng. 90, 104-118.

Roux, Y., Durand, M., Leroyer, A., Queutey, P., Visonneau, M., Raymond, J., Finot, J., Hauville, F., Purwanto, A., 2008. Strongly coupled VPP and CFD RANSE code for sailing yacht performance prediction. In: Proceedings of the 3rd High Performance Yacht Design Conference. Auckland, New-Zealand.

Sacher, M., Hauville, F., Bot, P., Durand, M., 2015. Sail trimming FSI simulation comparison of viscous and inviscid flow models to optimise upwind sail trim. In: Proceedings of 5th High Performance Yacht Design Conference. Auckland, New-Zealand.

Shankaram, S., Doyle, T., Gerritsen, M., Gianluca, I., Jameson, A., 2002. Improving the design of sails using CFD and optimization algorithms. In: Proceedings of High Performance Yacht Design Conference. Auckland, New-Zealand.

Viola, I.M., Bot, P., Riotte, M., 2013. Upwind sail aerodynamics: a RANS numerical investigation validated with wind tunnel pressure measurements. Int. J. Heat Fluid Flow 39, 90-101. http://dx.doi.org/10.1016/j.ijheatfluidflow.2012.10.004.

Viola, I.M.,, Flay, Richard G., 2010. Full-scale pressure measurements on a Sparkman and Stephens 24-foot sailing yacht. J. Wind Eng. Ind. Aerodyn. 98, 800-807. http://dx.doi.org/10.1016/j.jweia.2010.07.004

Yoo, J., Kim, H.T., 2006. Computational and experimental study on performance of sails of a yacht. Ocean Eng. 33, 1322-1342. http://dx.doi.org/10.1016/j. oceaneng.2005.08.008. 